\title{
Hyoid Bone
}

National Cancer Institute

\section{Source}

National Cancer Institute. Hyoid Bone. NCI Thesaurus. Code C32752.

A U-shaped bone supporting the tongue. This bone is located at the base of the tongue and is suspended from the tips of the styloid processes of the temporal bones by the stylohyoid ligaments. 